\title{
CARDIOPROTECTIVE EFFECT OF MENTHA LONGIFOLIA AGAINST CYCLOPHOSPHAMIDE INDUCED CARDIOTOXICITY IN RATS: A BIOCHEMICAL, ELECTROCARDIOGRAPHIC AND HISTOPATHOLOGICAL STUDY
}

\author{
AYSHATH AFROOS SHAHANA A. R. ${ }^{*}$, SANJIV KARALE, JAGADISH V. KAMATH \\ Department of Pharmacology, Shree Devi College of Pharmacy, Airport Road, Kenjar, Mangaluru 574142, karnataka, India \\ Email: afrooshahana@gmail.com
}

Received: 22 May 2016 Revised and Accepted: 22 Jul 2016

\section{ABSTRACT}

Objective: The current research was designed to evaluate the cardioprotective activity of Mentha longifolia (ML) leaf extract on cyclophosphamideinduced cardiotoxicity in rats.

Methods: Cardiotoxicity was induced in Albino wistar rats of either sex by administering a single injection of cyclophosphamide (200 mg/kg, i. p.) on the first day of the experimental period. Mentha longifolia $(250$ and $500 \mathrm{mg} / \mathrm{kg}$, p. o.) was administered daily for $10 \mathrm{~d}$ immediately after administration of cyclophosphamide on the first day. The general observations such as oxidative marker enzyme assays, ECG and histopathology were examined.

Results: Cyclophosphamide administration significantly $(\mathrm{p}<0.05)$ increased lipid peroxidation $(\mathrm{LPO})$ and decreased the levels of antioxidant markers such as superoxide dismutase (SOD) and catalase (CAT). Cyclophosphamide elevated the levels of biomarker enzymes like creatine kinase isoenzyme MB (CK-MB), creatine kinase isoenzyme NAC (CK-NAC) and lactate dehydrogenase (LDH). Further, the cyclophosphamide-treated rats showed changes in electrocardiographic parameters. Treatment with Mentha longifolia significantly $(\mathrm{p}<0.05)$ reversed the status of cardiac biomarkers, ECG and oxidative enzymes in cyclophosphamide-induced cardiotoxicity. Histopathological examination was also supported the potential cardioprotective effect of Mentha longifolia with reduced damage to the myocardium.

Conclusion: The biochemical, ECG and histopathology reports support the potential benefits of Mentha longifolia against myocardial damage which could be attributed to antioxidant activity.

Keywords: Cardioprotective, Cyclophosphamide, Mentha longifolia, ECG

(C) 2016 The Authors. Published by Innovare Academic Sciences Pvt Ltd. This is an open access article under the CC BY license (http://creativecommons. org/licenses/by/4. 0/) DOI: http://dx.doi.org/10.22159/ijpps.2016v8i9.13004

\section{INTRODUCTION}

Cytotoxicity is the one of the most undesirable side effect caused by the antineoplastic chemotherapeutic agents due to it's diverse action modes. Chemotherapeutic agents induced cardiotoxicity is very common, particularly in the case of alkylating agents [1]. Cyclophosphamide (CYP) is a bifunctional oxazaphosphorine alkylating agent widely used in the treatment of many neoplastic diseases. Breast carcinoma, acute lymphoblastic leukemia, nonHodgkin's lymphoma and a variety of bone and soft tissue sarcomas were treated using this nitrogen mustard type alkylating agent [2]. Along with tumor selectivity and a wide spectrum of clinical uses, CYP also causes multiple organ toxicities [3]. An acute type of cardiotoxicity is observed at a high dose of CYP within $10 \mathrm{~d}$ of its administration. Fatal complications such as congestive heart failure, arrhythmias, cardiac tamponade and myocardial depression were seen followed by myopericarditis [4].

The precise mechanism of CYP-induced cardiac toxicity has not been established. CYP undergoes extensive metabolism via the cytochromeP450 enzymatic system to produce active and inactive metabolites, namely phosphoramide mustard and acrolein respectively [5]. CYP metabolites provoked oxidative stress and direct endothelial capillary damage with resultant extravasation of proteins, erythrocytes, and toxic metabolites. Breakdown of endothelial cells in the presence of toxic metabolites causes direct damage to the myocardium and capillary blood vessels resulting in edema, interstitial hemorrhage and formation of microthrombi. As a result, CYP has developed an acute heart failure and arrhythmias [6].

Traditionally natural products and herbal medicines have been used to avoid side effects caused during treatments of various ailments. Antioxidants such as polyphenols, phenols and flavonoids are produced by the plants in a significant amount. These compounds are potential chemopreventive agents, due to their hydrogen- donating and metal-chelating capacities. Moreover, some studies have shown that plant base natural products could provide protection against cyclophosphamide-induced toxicities [7].

Mentha longifolia is the herb belongs to the family Lamiaceae, which is used for the treatment of bronchitis, flatulence, anorexia, ulcerative colitis and liver complaints due to their antiinflammatory, carminative, antiemetic, diaphoretic, antispasmodic, analgesic, stimulant, emmenagogue and anti-cathedral activities [8].

Flavonoid consumption prevents many cardiovascular diseases [9]. Mentha longifolia contain mainly five flavonoids identified as luteolin-7-0-glycoside, luteolin-7,3-0-diglycoside, apigenin, quercetin-3-0-glycoside and kaempferol-3-0-glycoside[10]. Among these molecules, the quercetin-3-0-glycoside had the highest antioxidant activity [9]. Moreover, Mentha longifolia is traditionally claimed for cardioprotective activity since it is used in the treatment of high blood pressure [11]. The other major components present are a cis-piperitone epoxide, piperitenone oxide, carvone, pulegone, menthone, thymol, menthol, $\beta$-thyione, carvacrol and (E)caryophyllene [12]. There is paucity for the availability of scientific evidence proving the cardioprotective activity of Mentha longifolia. Hence, the present study was designed to evaluate the cardioprotective activity of ethanol extract of Mentha longifolia.

\section{MATERIALS AND METHODS}

\section{Chemicals and reagents}

All chemicals and reagents used were of analytical grade and purchased from standard companies. Cyclophosphamide (zydus oncosciences, Ahmedabad, India), Sterile water for injection-IP (Ives drugs Pvt. Ltd, India), Ketamine (Neon pharmaceutical Ltd, Mumbai, India), xylazine (Indian immunological, Guntur, India), Sucrose (Merck Specialities Pvt. Ltd, Mumbai, India). Biochemical kits were procured from accucare (Gujarat, India). 


\section{Preparation of Mentha longifolia extract}

The plant of Mentha longifolia (Voucher specimen No. Kacst 00765) was collected from Riyad, KSA in the month of September 2015. The material was procured and identified by Dr. Shanavaskhan $\mathrm{AE}$, scientist, king abdulaziz city for science and technology, Riyad, KSA. The leaves were cut into small pieces and shade dried. It was then coarsely powdered and extracted using ethanol $(80 \%)$ by maceration process. The obtained ethanolic extracts were filtered and evaporated by using a rotary evaporator and freeze dryer respectively to give the crude dried extract [9]. The yield was found to be $15.38 \%(\mathrm{~W} / \mathrm{W})$. The extract was freshly dissolved in tween $80 \%$ before giving each dose to animals.

\section{Experimental animals}

Healthy adult Albino wistar rats of either sex weighing 170-250g were housed in standard polypropylene cages and maintained under controlled room temperature $\left(25^{\circ} \pm 5{ }^{\circ} \mathrm{C}\right)$ and relative humidity $(55 \pm 5 \%)$ in a well-ventilated animal house under $12: 12 \mathrm{~h}$ light and dark cycle at the central animal house, shree devi college of pharmacy, Mangaluru. All the rats were provided with commercially available standard pellet diet, water ad libitum. The animals were maintained under standard conditions in the animal house as per the guidelines of Committee for the Purpose of Control and Supervision on Experiments on Animals (CPCSEA). The Institutional Animal Ethics Committee approved the experimental protocol (SDCP/IAEC-01/2014-15).

\section{Experimental protocol}

The Albino wistar rats of either sex were divided into five groups of six animals each. Group I served as normal control $(1 \mathrm{ml} / \mathrm{kg}$ of $0.5 \%$ carboxymethyl cellulose) for $10 \mathrm{~d}$. Group 2 animals were administered with a single dose of CYP $(200 \mathrm{mg} / \mathrm{kg}$, i. p) on the first day of the experimental period and served as cyclophosphamide control group. Group 3 animals were treated with ethanolic extract of Mentha longifolia (500 mg/kg, p. o) alone for $10 \mathrm{~d}$. Group 4 and group 5 animals received a single dose of CYP $(200 \mathrm{mg} / \mathrm{kg}$, i. p) on first day of the experimental period followed by the administration of ethanolic extract of Mentha longifolia $250 \mathrm{mg} / \mathrm{kg}$ and $500 \mathrm{mg} / \mathrm{kg}$ continuously for $10 \mathrm{~d}$ by oral route respectively [13].

\section{Oxidative marker enzymes assay}

Twenty-four hour after the last treatment, blood was collected by retro-orbital puncture and the serum was separated by centrifugation at $5000 \mathrm{rpm}$ for $10 \mathrm{~min}$. The isolated serum was subjected for assay of marker enzyme namely creatine kinase- MB (CK-MB), creatine kinase-NAC (CK-NAC) and lactate dehydrogenase (LDH). Estimation of marker enzymes was done by using commercial kits with the help of semi- auto analyzer (model: Prietest touch, Robonik India PVT. LTD.).
Then the animals were sacrificed by mild ether anesthesia. The heart tissue was homogenized with sucrose solution $(0.25 \mathrm{M})$ for estimations of superoxide dismutase (SOD), catalase (CAT) and lipid peroxidation (LPO) $[13,14]$.

\section{Electrocardiographic studies}

Twenty-four hour after the last treatment, the animals were anesthetized with the combination of ketamine $(75 \mathrm{mg} / \mathrm{kg}$, i. p.) and xylazine $(8 \mathrm{mg} / \mathrm{kg}$, i. p.). Leads were attached to the dermal layer of both the semiflexed front paws and slightly extended hind legs of a rat lying straight on the back and recordings were made with the help of digital physiograph (model no-. DI-2, INCO, Ambala city, India). The changes in heart rate, QRS interval, QT interval, PR interval and RR interval were determined [13].

\section{Histopathological evaluation}

The heart tissue was dissected and fixed in $10 \%$ neutral buffered formalin for approximately $48 \mathrm{~h}$. The paraffin sections were prepared on a glass slide and stained with hematoxylin and eosin for subsequent microscopic evaluation [14].

\section{Statistical analysis}

Results are expressed as mean \pm SEM. Statistical significance was assessed using one-way analysis of variance (ANOVA) followed by Tukey-Karmer multiple comparison tests. $\mathrm{P}<0.05$ was considered significant.

\section{RESULTS}

\section{Serum enzyme biomarkers}

CYP control group demonstrated a significant increase in serum CK- MB, CK- NAC, LDH values compared to normal control. Mentha longifolia (ML, $250 \mathrm{mg} / \mathrm{kg}$ and $500 \mathrm{mg} / \mathrm{kg}$ ) treated rats significantly decreased the CK-MB, CK- NAC, LDH values in dose-dependent fashion compared to CYP control group [table 1].

\section{Effect on SOD and catalase}

SOD and catalase activity were reduced significantly in CYP control compared to normal control. Experimental groups such as Mentha longifolia $(250 \mathrm{mg} / \mathrm{kg}$ and $500 \mathrm{mg} / \mathrm{kg})$ treated groups resulted in significant improvement in SOD and catalase activity compared to the CYP-treated group [table 2].

\section{Effect on lipid peroxidation}

CYP control group exhibited a significant increase in LPO levels compared to normal control. Mentha longifolia treatment in a dosedependent manner demonstrated a significant reduction in LPO levels compared to CYP control group [table 2].

Table 1: Effect of M. longifolia on serum level of CK-MB, CK-NAC and LDH in CYP-induced cardiotoxicity in rats

\begin{tabular}{lll}
\hline Treatment & CK-MB (IU/I) & CK-NAC (IU/I) \\
\hline Normal control & $39.64 \pm 1.28$ & $69.99 \pm 0.67$ \\
Cyclophosphamide (CYP) control & $251.87 \pm 2.07^{* * *}$ & $366.51 \pm 7.94^{* * *}$ \\
Mentha longifolia (ML) & $34.59 \pm 2.68^{\mathrm{ns}}$ & $54.96 \pm 0.21^{\mathrm{ns}}$ \\
CYP+ML 250 mg/kg & $90.73 \pm 0.66^{* * * \# \#}$ & $113.83 \pm 1.22$ \\
CYP+ML 500 mg/kg & $31.28 \pm 0.70^{* \# \# \#}$ & $192.59 \pm 1.85^{* * * \# \#}$ \\
\hline
\end{tabular}

CK- MB-creatine kinase- MB, CK-NAC-creatine kinase-NAC, LDH-lactate dehydrogenase, IU/l-International units per litre., All the values are in mean \pm SEM, $n=6 . n s=$ not significant, ${ }^{* * *} \mathrm{P}<0.001$ when compared to normal, ${ }^{\# \# \# P}<0.001$ when compared to $C Y \mathrm{P}$ control.

Table 2: Effect of $M$. longifolia on antioxidants SOD, Catalase and Lipid peroxidation in CYP-induced cardiotoxicity in rats

\begin{tabular}{llll}
\hline Treatment & SOD (Unit/mg protein) & Catalase (Unit/mg protein) & Lipid peroxidation (Unit/mg protein) \\
\hline Normal control & $25.59 \pm 0.81$ & $61.04 \pm 0.26$ & $2.74 \pm 0.11$ \\
Cyclophosphamide (CYP) control & $14.76 \pm 0.19^{* * *}$ & $34.14 \pm 0.42^{* * *}$ & $7.79 \pm 0.06^{* * *}$ \\
Mentha longifolia (ML) & $26.91 \pm 0.51^{\mathrm{ns}}$ & $62.18 \pm 0.17 \mathrm{~ns}$ & $2.52 \pm 0.20^{\mathrm{ns}}$ \\
CYP+ML 250 mg/kg & $20.56 \pm 0.31^{* * \# \# \#}$ & $40.16 \pm 0.20^{* * * \# \#}$ & $6.79 \pm 0.06^{* * * \# \#}$ \\
CYP+ML 500 mg/kg & $22.14 \pm 0.30^{* * \# \# \#}$ & $49.24 \pm 0.23^{* * * \# \#}$ & $4.79 \pm 0.09^{* * * \# \# \#}$ \\
\hline
\end{tabular}

SOD-superoxide dismutase, Unit/mg protein-Unit per milligram protein, All the values are in mean \pm SEM, $n=6$. ns= not significant, ${ }^{* *} \mathrm{P}<0.001$ when compared to normal, \#\#\# $\mathrm{P}<0.001$ when compared to CYP control. 
Table 3: Effect of M. longifolia on heart rate and electrocardiographic parameters in CYP-induced cardiotoxicity in rats

\begin{tabular}{|c|c|c|c|c|c|}
\hline Treatment & $\begin{array}{l}\text { Heart rate } \\
\text { (Beats/min.) }\end{array}$ & QRS duration (ms) & QT segment (ms) & RR interval (ms) & PR interval (ms) \\
\hline Normal control & $361.33 \pm 1.76$ & $28.33 \pm 0.09$ & $70.88 \pm 0.36$ & $28.89 \pm 0.07$ & $62.45 \pm 0.18$ \\
\hline Cyclophosph-amide (CYP) control & $272.33 \pm 2.02^{* * *}$ & $31.58 \pm 0.26^{* * *}$ & $106.73 \pm 0.26^{* * *}$ & $39.22 \pm 0.15^{* * *}$ & $85.72 \pm 0.02^{* * *}$ \\
\hline Mentha longifolia (ML) & $363.00 \pm 2.08^{\mathrm{ns}}$ & $28.14 \pm 0.08^{\mathrm{ns}}$ & $70.84 \pm 0.15^{\mathrm{ns}}$ & $28.82 \pm 0.12^{\mathrm{ns}}$ & $62.28 \pm 0.16^{\mathrm{ns}}$ \\
\hline $\mathrm{CYP}+\mathrm{ML} 250 \mathrm{mg} / \mathrm{kg}$ & $295.93 \pm 3.26^{* * * \# \#}$ & $30.14 \pm 0.08^{* * * \# \# \#}$ & $96.41 \pm 0.22^{* * * \# \# \#}$ & $37.88 \pm 0.10^{* * * \# \# \#}$ & 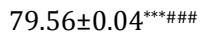 \\
\hline $\mathrm{CYP}+\mathrm{ML} 500 \mathrm{mg} / \mathrm{kg}$ & 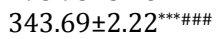 & 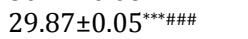 & $79.45 \pm 0.18^{* * * \# \# \#}$ & $31.85 \pm 0.07^{* * * \# \# \#}$ & $63.66 \pm 0.12^{* * * \# \# \#}$ \\
\hline
\end{tabular}

Beats/min.-beats per minute, ms-millisecond., All the values are in mean $\pm \mathrm{SEM}, \mathrm{n}=6$. ns $=$ not significant, ${ }^{* * *} \mathrm{P}<0.001$ when compared to normal, \#\#\#P<0.001 when compared to CYP control.

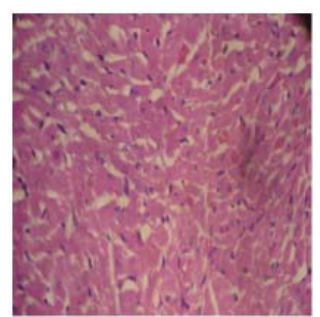

(a)

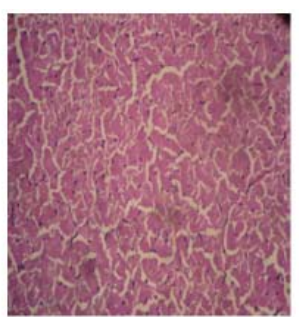

(b)

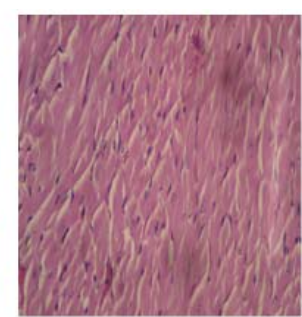

(c)

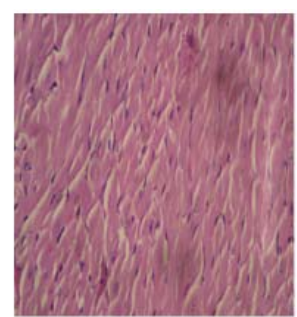

(d)

Fig. 1: (a) (H and E) stained microscopic section of normal control group (normal texture of cell) (b) (H and E) stained microscopic section of CYP $(200 \mathrm{mg} / \mathrm{kg}$, i. p.) control group (Necrotic cells with degeneration of myofibril, increased interstitial space, diffused inflammation)

(c) (H and E) stained microscopic section of ML $(250 \mathrm{mg} / \mathrm{kg}$, p. o.) and CYP $(200 \mathrm{mg} / \mathrm{kg}$, i. p.) (less interstitial space and myofibrillar degeneration) (d) (H and E) stained microscopic section of ML $(500 \mathrm{mg} / \mathrm{kg}$, p. o.) and CYP (200 mg/kg, i. p.) (Small multifocal degeneration, slight inflammation, fall in interstitial space)

\section{Effect on electrocardiographic parameters}

CYP control group reported a significant decrease in heart rate and a significant increase in QRS duration, QT segment, PR and RR interval compared to normal control. ML treated group rectified CYP-induced changes in ECG to normal in dose-dependent manner [table 3].

\section{Histopathological observations}

CYP control group showed the distorted structure of heart tissue by necrosis of the cells with degeneration of myofibril, increased interstitial space and diffused inflammation compared to normal control group. The treatment groups treated with low dose of ML (250 $\mathrm{mg} / \mathrm{kg}$ ) showed moderate myocardial damage with less interstitial space and myofibrillar degeneration and high dose of ML (500 mg/kg) showed effective inhibition of CYP-induced cardiac damage by reversal of infiltration of inflammatory cells and fragmentation of myofibrils when compared to CYP control group [fig. 1].

\section{DISCUSSION}

The aim of the present study was to investigate the effect of ML leaf extract against CYP-induced myocardial toxicity.

From the documented results, it can be concluded that ML leaf extract (250 and $500 \mathrm{mg} / \mathrm{kg}$, p. o.) showed beneficial results dose dependently.

Mentha longifolia contain different flavonoids, monoterpene ketones, tannins and saponins which are responsible for different pharmacological and biological activity of these plants [15]. Flavanoids are a class of polyphenolic substances with free radical scavenging, inhibition of hydrolytic and oxidative enzymes properties [16]. It also has anti-inflammatory, anti-allergic, antiviral, anti-aging and anti-carcinogenic activity. Antioxidant properties of the flavonoids leads to it's broad therapeutic effects. Besides this, flavanoid compounds may exert protection against heart disease through the inhibition of cyclooxygenase and lipoxygenase activities in platelets and macrophages [17].

Cardiotoxicity is caused due to the destructive effect of CYP. CYP mediates production of xanthine oxidase which catalyses the oxidation of hypoxanthine to xanthine and generates superoxide and uric acid. Superoxide is known to generate reactive oxygen species [18]. Intracellular antioxidation systems play an important role in detoxifying the reactive oxygen species (ROS), which is interfered by the toxic metabolites of CYP and the drug itself [19]. Thus, free radical production is increased and anti-oxidant enzymes are decreased in the presence of CYP. Lipid peroxidation is also induced [18].

In our present finding, animals treated with only CYP demonstrated a significant decrease in SOD, Catalase and a significant increase in lipid peroxidation, which indicates the induction of myocardial toxicity. Prophylactic treatment with Mentha longifolia dosedependently increase SOD and Catalase activity and decrease lipid peroxidation level which justify its protection.

The marker enzymes such as CK-MB, CK-NAC and LDH were leaked from the myocytes to the blood due to CYP-induced myocardial damage. Hence to detect myocardial necrosis, these marker enzymes were estimated [20].

In the present study, experimental animals treated with CYP without any other treatment reflected the remarkable amount of increase in serum marker enzymes levels which confirms the induction of myocardial toxicity. Mentha longifolia dose-dependently restored the marker enzymes levels.

In the present study, CYP showed abnormal changes in an electrocardiographic pattern such as a decrease in heart rate and an increase in RR, PR and QT intervals and prolongation of QRS interval. Abnormal changes in ECG parameters were also found to be extremely significant ( $\mathrm{p} \leq 0.001)$ compared to normal control.

The release of a significant amount of acetylcholine is one of the main reason for decreased heart rate, which is also linked with the genesis of myocardial damage [21]. In the present study, QT prolongation in CYP-treated group may be due to increasing in the cellular $\mathrm{Na}+$ content and decrease in $\mathrm{K}+$ content. Change in parasympathetic tone and conduction system deformation can cause AV block, which in turn leads to prolongation of PR interval associated with CYP [22].

Mentha longifolia in both $250 \mathrm{mg} / \mathrm{kg}$ and $500 \mathrm{mg} / \mathrm{kg}$ doses, in a dose-dependent manner, bring back the ECG parameters towards the normal.

A histological study in CYP-induced cardiotoxicity supported the findings of other parameters analyzed in different treatment groups. 
For the normal heart, myocardial fibers were found to be of uniform size, shape, and configurations with no inflammatory cell infiltrates. Treatment with Mentha longifolia doses dependently inhibited CYP induced cardiac damage by decreasing fragmentation of myofibrils and inflammation. Mentha longifolia predominantly in higher dose $(500 \mathrm{mg} / \mathrm{kg})$ was able to retrieve the pathological changes associated with CYP in myocardial cell. The phytoconstituents such as flavonoids, tannins, and saponins along with others in ML may be providing the protective effect against CYP-induced cardiotoxicity.

\section{CONCLUSION}

It can be concluded from the present study that CYP treatment causes pronounced oxidative stress and tissue damage in the heart. Administration of ML extract protects the CYP-induced cardiotoxicity in dose-dependent manner. Biochemical, ECG and histopathological studies confirm the cardioprotective role of Mentha longifolia. Future studies can be carried out to establish the fact clinically.

\section{ACKNOWLEDGEMENT}

Authors would like to thank Dr. Shanavaskhan AE, scientist, king abdulaziz city for science and technology, Riyad, KSA for identification of plant Mentha longifolia. The authors are also sincerely thankful to the management of Shree Devi College of Pharmacy, Mangaluru, India for their constant encouragement and support and providing all the necessary facilities for carrying out this study.

\section{CONFLICT OF INTERESTS}

\section{Declared none}

\section{REFERENCES}

1. Subramani PC, Sasivarnam T, Krishnan G, Selvanathan I, Mani G, Ramasamy E, et al. Impact of geraniol on cyclophosphamide provoked cardiotoxic properties-An in vivo study. Int J Pharm Pharm Sci 2015;7:420-6.

2. Stanklewicz A, Skyzydlewska E. Amifostine antioxidant effect on serum of rats treated with cyclophosphamide. Pol J Environ Stud 2005;14:341-6.

3. Desouza CA, Santini G, Marino G, Nati S, Congiu AM, Vigorito AC, et al. Amifostine (WR-2721), a cytoprotective agent during highdose cyclophosphamide treatment of non-hodgkin's lymphomas: a phase II study. Braz J Med Biol Res 2000;33:791-8.

4. Goldberg MA, Antin JH, Guinan EC, Rappeport JM. Cyclophosphamide cardiotoxicity: an analysis of dosing as a risk factor. Blood 1986;68:1114-8.

5. Becker H, Potyka P, Weber C, Renelt M, Federlin K. T-helper cell subsets in patients with inflammatory rheumatic diseases undergoing immunosuppressive therapy. Immun Infekt 1991;19:26-7.

6. Yeh ETH, Tong AT, Lenihan DJ, Yusuf W, Swafford J, Champion $\mathrm{C}$, et al. Cardiovascular complications of cancer therapydiagnosis, pathogenesis and management. Am Heart Assoc 2004;109:3122-31.

7. Angie MAM, Paka GD, Ntentie FR, Dimodi H, Ngondi JL, E nyong JO. Protective effect of a hydroethanolic extract of Solanum scabrum and Cola verticillata against cyclophosphamide induced toxicity in female rats. J Food Res 2014;3:18-30.
8. Dzamic AM, Sokovic MD, Ristic MS, Novakovic M, GrujicJovanovic $\mathrm{S}$, Tesevic $\mathrm{V}$, et al. Antifungal and antioxidant activity of Mentha longifolia (L.) Hudson (Lamiaceae) essential oil. Botanica Serbica 2010;34:57-61.

9. Sandhar HK, Kumar B, Prasher S, Tiwari P, Salhan M, Sharma P. A review of phytochemistry and pharmacology of flavanoids. Int Pharm Sci 2011;1:25-41.

10. Akroum S, Bendjeddou D, Satta D, Lalaoui K. Antibacterial activity and acute toxicity effect of flavanoids extracted from Mentha longifolia. Am-Eurasian J Sci Res 2009;4:93-6.

11. Alamgeer, Akhtar MS, Jabeen Q, Bashir S, Malik MNH, Khan HU, et al. Antihypertensive and toxicity studies of aqueous methanolic extract of Mentha longifolia L. J Anim Plant Sci 2013;23:1622-7.

12. Sharopov F, Sulaimonova VA, Setzer WN. Essential oil composition of Mentha longifolia from wild populations growing in Tajikistan. J Med Act Plants 2012;1:76-84.

13. Viswanathaswamy AHM, Patel UM, Koti BC, Gadad PC, Patel NL, Thippeswamy AHM. Cardioprotective effect of Saraca indica against cyclophosphamide-induced cardiotoxicity in rats: a biochemical electrocardiographic and histopathological study. Indian J Pharmacol 2013;45:44-8.

14. Chakraborty M, Asdaq SM. Interaction of Semecarpus anacardium L. with propranolol against isoproterenol induced myocardial damage in rats. Indian J Exp Biol 2011;49:200-6.

15. Razavi SM, Zarrini G, Molavi G. The evaluation of some biological activities of Mentha longifolia (L.) Huds. growing wild in Iran. Pharmacologia 2012;3:535-8.

16. Khan RA, Khan NA, Khan FU, Ahmed M, Shah AS, Khan MR, et al. Phytochemical, antioxidant and cytotoxic activities of Periploca aphyla and Mentha longifolia, selected medicinal plants of district Bannu, Pakistan. Afr J Pharm Pharmacol 2012;6:3130-5.

17. Percival M. Antioxidants. Clin Nutr Insights; 1998. p. 1-4.

18. Sekeroglu V, Aydin B, Sekeroglu ZA. Viscum album L. extract and quercetin reduce cyclophosphamide-induced cardiotoxicity, urotoxicity, and genotoxicity in mice. Asian Pac J Cancer Prev 2011;12:2925-31.

19. Yener NA, Sinanoglu O, Ilter E, Celik A, Sezgin G, Midi A, et al. Effects of spirulina on cyclophosphamide-induced ovarian toxicity in rats: a biochemical and histomorphometric evaluation of the ovary. Biochem Res Int 2013:1-6. Doi.org/10.1155/2013/764262.

20. Shanmugarajan TS, Arunsunder M, Somasundaram I, Krishnakumar E, Sivaraman D, Ravichandiran V. Protective effect of Ficus hispida Linn. on cyclophosphamide provoked oxidative myocardial injury in rat model. Int J Pharmacol 2008;1:1-10.

21. Atlee JL. Protective cardiac dysrhythmias: diagnosis and management. Anesthesiology 1997;86:1397-424.

22. Levine ES, Friedman HS, Griffith OW, Colvin OM, Raynor JH, Lieberman M. Cardiac cell toxicity induced by 4-hydroperoxycyclophosphamide is modulated by glutathione. Cardiovasc Res 1993;27:1248-53.

\section{How to cite this article}

- $\quad$ Ayshath Afroos Shahana AR, Sanjiv Karale, Jagadish V Kamath. Cardioprotective effect of Mentha longifolia against cyclophosphamide-induced cardiotoxicity in rats: a biochemical, electrocardiographic and histopathological study. Int J Pharm Pharm Sci 2016;8(9):214-217. 